\title{
The city surface as a heavy metal emission source
}

\author{
B. Müller, G. Schöller \& P. H. Brunner \\ Institute of Water Quality, Resources and Waste Management, \\ Vienna University of Technology, Austria
}

\begin{abstract}
Urban surfaces, such as roofs and walls of buildings, surfaces of transport systems (roads, rails, vehicles etc.), and of networks are steadily degraded by processes like corrosion and wear, resulting in emissions to the environment. Although material flows of surfaces are small compared to total mass flows of cities, they might be of environmental importance. Methods are developed (1). to determine the amount of urban surface materials exposed to the atmosphere, and (2). to assess material flows resulting from the deterioration and wear of urban surfaces to the environment. A case study is presented, focusing on the understanding of the interaction of urban surfaces as a whole and not on the behavior of individual surfaces. The significance of urban surfaces as sources of metals in the environment is discussed.
\end{abstract}

Keywords: surface, city, diffuse emission, heavy metal, copper, zinc, material flow analysis.

\section{Introduction}

Cities have a metabolism comparable to living organisms: they need energy, nutrients, water and have a surface that protects them from weathering and deterioration. They release waste products such as off-gas (e.g. $\mathrm{CO}_{2}$ ), waste water, solid wastes and emissions. For a proper and sustainable functioning, the urban metabolism must be known, evaluated, and constantly adapted to rapidly changing conditions. On the supply side, the flow of materials is mainly controlled by market forces and adapts quickly to changes in demand due to population growth and purchasing power. In contrast, on the back end, there are less market forces. 
To understand city metabolism becomes increasingly important because the urban way of life becomes the predominant life style on a global level. More and more people live in cities, and the amount of megacities has roughly doubled in the last 25 years (figure 1).

number of megacities

(<5Mio. inhabitants)

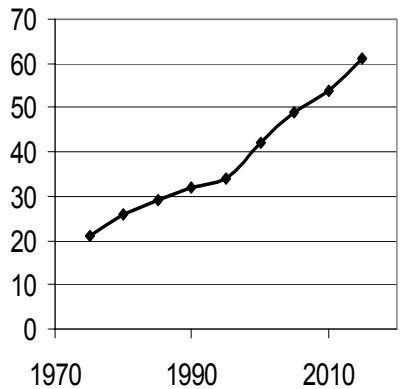

persons living in cities $\left(10^{y}\right)$

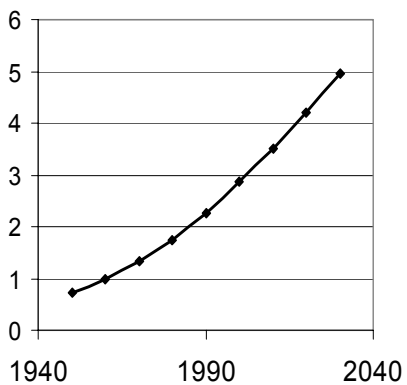

Figure 1: Global number and inhabitants of mega-cities (data from United Nations [1]).

While many aspects of the urban metabolism have been and are being studied intensively, the topic of the total interaction of the city surface with the environment is a comparatively new issue. As a consequence of this interaction, pollutants as heavy metals are released diffusely by the city surface and transported to the environment. In order to focus on the topic, the term "city surface" has to be defined: in the following, "city surface" is used for all surfaces of constructions, networks, and man made (= anthropogenic) goods in a city that are exposed to the environment. This definition includes roofs, facades, surfaces of roads, cars, light poles, masts and cables for the transmission of power and information. It does not include the soil as a surface, neither parks, private and public gardens, and the like, even if it is recognized that they contribute also to the surface of a city. In the past, environmental concern was mainly on emissions from production of materials. However, in the 1990s Bergbäck [2] showed that metal emissions that are caused by corrosion or wear of the city surface during the consumption phase of materials exceed emissions of production processes in urban areas. For instance exposed surfaces of vehicles, roads and buildings cause nearly $50 \%$ of total copper emissions in Stockholm (Landner and Linneström [3]). In this presentation the results of an assessment of the material flows resulting from the deterioration of surfaces to the environment in an urban area in Austria are shown.

\section{The urban metabolism}

In order to describe the metabolism of urban areas the method of material flow analysis (MFA) is used to frame flows and stocks within a defined area. MFA connects the sources, paths and sinks of a material in a system defined by space 
and time. Transport, transformation and storage of materials characterize different processes of the system. Because of the law of the conservation of matter, the results of an MFA can be controlled by a simple material balance comparing all inputs, stocks and outputs of a process (Brunner and Rechberger, [4]). The total flow of materials in any city is dominated by rapid flows of large masses of materials such as water, sewage, air and off-gas as shown in figure 2 by the example of Vienna. The stock of $350 \mathrm{t}$ per capita largely contains of mineral building materials. The stock is growing by 4 to $10 \mathrm{t}$ per capita every year. Therefore, material turnover and the stock of materials in cities are still increasing.

In comparison to the dominating material flows the amounts of emissions are tiny. However, although mass flows are small emissions might be environmentally relevant as they are partly transferred to soils and water bodies. An assessment of heavy metal concentration in Stockholm's sediments showed that concentrations increase towards the city (Lindström et al. [6]). Figure 3 shows the mercury concentration in Stockholm's sediments. As high concentrations are spread diffusely in the city the hypothesis that emissions largely result from consumption of materials and not from point sources as production processes is confirmed. Although several studies show the flows of materials from individual urban surfaces to air, water and soil (e.g. Bergbäck et al. [8] and Sörme [7]) none of these studies discusses the relevance yet in view of other pressures on the environment. However, considering the large global increase in urban population and in per capita material turnover, it is likely that, in the long term, surface derived material flows will contribute substantially to the overloading of the carrying capacities of soils and waters in and around large cities. Therefore, it is necessary to increase knowledge on surface emission flows.

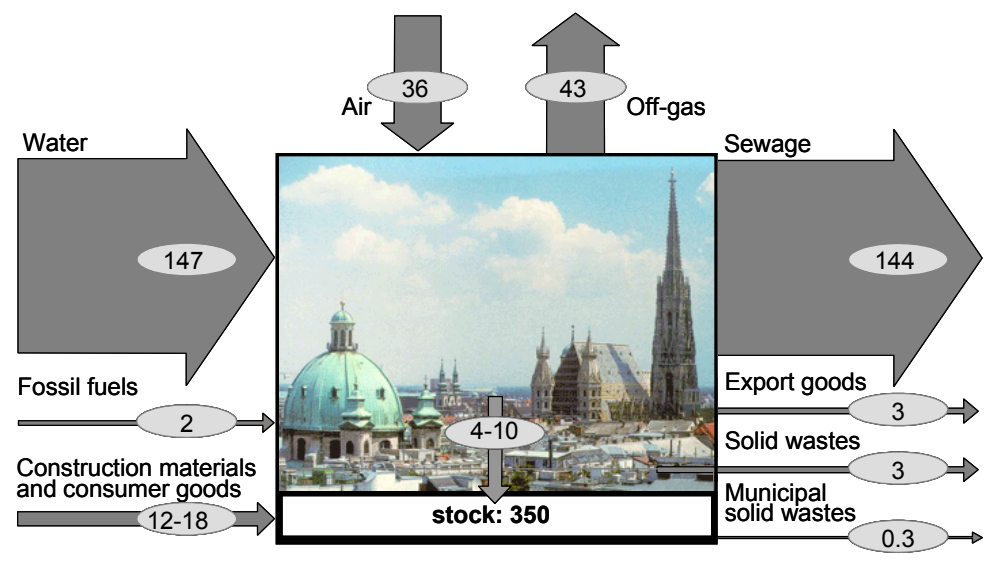

Figure 2: Material flows of Vienna (flows: tons per capita and year, stocks: tons per capita; from Brunner, P.H. and Rechberger, H., in Encyclopedia of Global Environmental Change, John Wiley \& Sons, 2001 [5], with permission). 


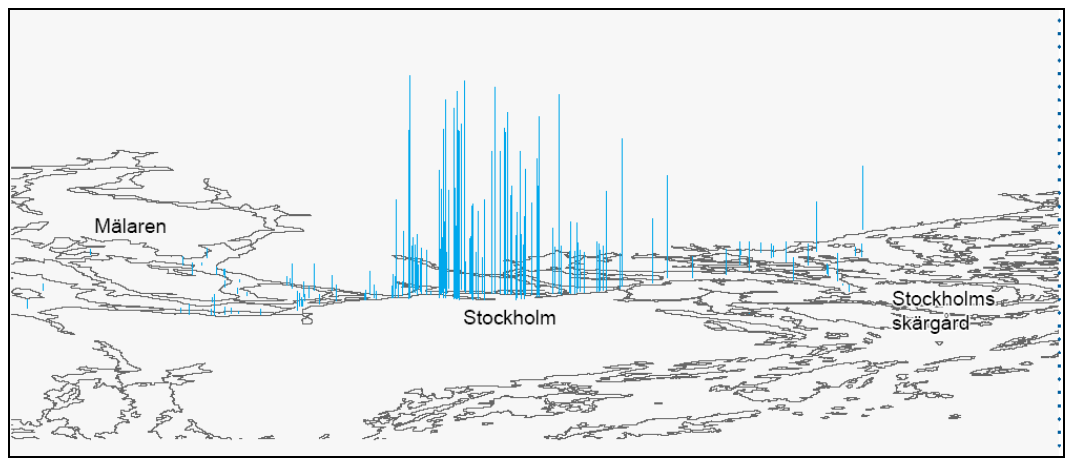

Figure 3: $\quad$ Mercury in Stockholm's sediments (Naturvardsverket [9]).

\section{3 "Measuring" the urban surface}

As it is not possible to directly measure surface emissions of a city the following steps are carried out in order to finally calculate emissions:

\subsection{Definition of system boundaries}

The urban area of Villach, located in southern Austria was chosen as study site. System boundaries are defined with a period of one year and the political border of the district of Villach. Villach is located in southern Austria and has about 58,000 inhabitants.

\subsection{Identification of emission sources}

Emission sources can be assigned to either vehicles or buildings and infrastructure. Surfaces of buildings, such as roofs, window sills or fences, the water supply and sewer system and road and railway infrastructure are considered as the most important sources of metal emissions. From vehicles most metals are emitted by wear of belts of tires and brake linings of motor and railway vehicles.

\subsection{Choice of substances}

The metals copper and zinc were chosen as they can be found in many surface materials. They are both essential elements for animals and plants, but toxic in high concentrations.

\subsection{Assessment of surface materials}

\subsubsection{Buildings}

The residential area of Villach was separated into four building categories that differed in housing density, purpose of use (e.g. residential or industrial) and building size (base area and number of floors). Orthophotos of Villach were used to calculate the proportion of building area in the different categories. A 
description of building categories, the percentage of building area and the areal percentage of each category are shown in table 1 . Category 1 is located in the outskirts of Villach and has rural character. Building area is lowest in this category and more than half of Villach's area belongs to category 1. Category 3, with the lowest areal percentage belongs to the city centre. Category 2 stands between categories 1 and 3. Category 4 is occupied by industrial and public buildings such as schools or train stations. The remaining area of $2,4 \%$, which is missing in table 1 , belongs to a river passing Villach that has not been assigned to a building category. Characteristic areas of every category were selected to collect data on the composition of buildings and kind and measure of exposed metals.

Table 1: $\quad$ Building categories of Villach.

\begin{tabular}{|clcccc|}
\hline category & description of buildings & $\begin{array}{c}\text { nr. of } \\
\text { floors }\end{array}$ & building area [\%] & usage & $\begin{array}{c}\text { percentage of } \\
\text { total area [\%] }\end{array}$ \\
\hline $\mathbf{1}$ & $\begin{array}{l}\text { free-standing buildings } \\
\text { (rural character) }\end{array}$ & 2 & $<10$ & mainly residential & 55 \\
\hline $\mathbf{2}$ & $\begin{array}{l}\text { row houses } \\
\text { (peripheral area) }\end{array}$ & $2-3$ & $10-20$ & mainly residential & 35 \\
\hline $\mathbf{3}$ & $\begin{array}{l}\text { multy-story residential buildings } \\
\text { (city) }\end{array}$ & $? \mathbf{3}$ & $20-40$ & residential & 2,3 \\
\hline $\mathbf{4}$ & $\begin{array}{l}\text { industrial, public buildings } \\
\text { (peripheral area and city) }\end{array}$ & $1-2$ & $20-40$ & $\begin{array}{c}\text { factories, office buildings, } \\
\text { schools, etc. }\end{array}$ & 5,0 \\
\hline
\end{tabular}

\subsubsection{Traffic}

Metals are emitted either by corrosion and run off of road and railway infrastructure or by wear of road course, tires, brake linings and in case of railway traffic wear of the contact wire.

Roads were separated into three different categories depending on the intensity of traffic as shown in figure 4. In Villach a daily traffic of motor vehicles of 1,392,000 km was observed (Röschl [10]). On representative parts of the three different road categories road infrastructure was recorded. Road infrastructure includes all kind of sign posts, traffic lights, noise and crash barriers and banisters for instance on bridges. As these elements have different size and surface a "standard" infrastructure of the three road categories was designed based on the records. Infrastructure elements are often galvanised or coated with a zinc containing paint. Therefore, a medium amount of galvanised and painted infrastructure elements was calculated for each road category.

In Villach trains cover a distance of $980 \mathrm{~km}$ per day. Necessary information on railway infrastructure, measure, exchange and number of brake linings per train were provided by the Austrian Railway Company.

\subsection{Determination of run off and abrasion rates}

Literature data on composition of asphalt course, tires and brake linings and on run off rates were applied to calculate emissions of Villach's surface.

\subsubsection{Buildings and infrastructure}

Zinc run off from painted surfaces is $0.7 \mathrm{~g} \mathrm{Zn} / \mathrm{m}^{2}$ per year Odnevall (Wallinder et al. [11]). Galvanised surfaces emit $3.1 \mathrm{~g} \mathrm{Zn} / \mathrm{m}^{2}$ per year and copper sheeting 1.3 $\mathrm{g} \mathrm{Cu} / \mathrm{m}^{2}$ per year (Persson and Kucera [12]). 


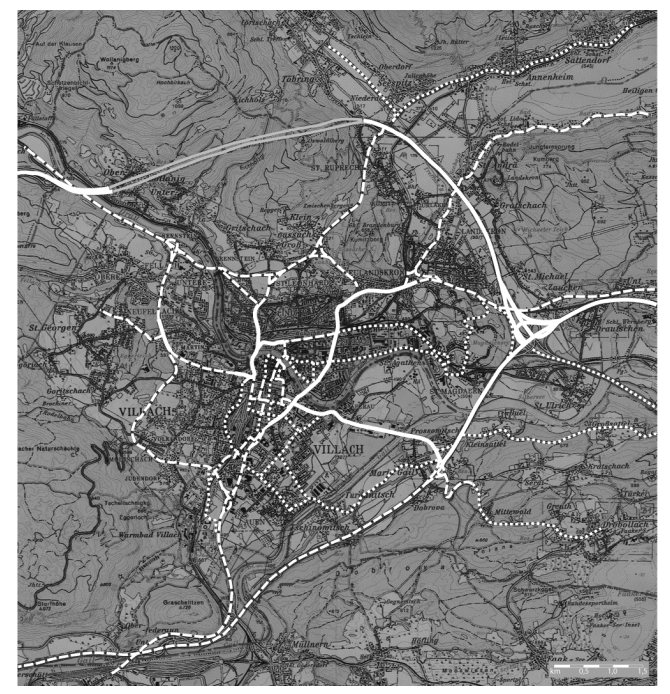

Figure 4: Road categories in Villach (solid line: 25,000, dashed line 15,000 and dotted line 5,000 vehicles per day).

\subsubsection{Traffic}

Tires contain about $1.6 \%$ zinc (Lohm et al. [13]) and wear about $0.2 \mathrm{~g} / \mathrm{km}$ (Haider [14]). Brake pads of front brakes and brake shoes of rear brakes have different concentrations of copper and zinc (Westerlund [15]). With the assumption that brake linings are exchanged when $70 \%$ of brake linings are worn off wear of front brakes amounts to $9.8 \mathrm{mg} / \mathrm{km}$ and wear of rear brakes $4.6 \mathrm{mg} / \mathrm{km}$. Wear of asphalt roads is mainly caused by use of studded tires (Lindgren [16], Jacobson and Hornwall [17]). A surface course of 95\% granite and 5\% bitumen was assumed for all roads in Villach. Studded tires are allowed only for 5 months per year and are used by approximately $10 \%$ of all vehicles. On average studded tires cause an emission rate of $3 \mathrm{~g}$ asphalt per vehicle and kilometre (Jacobson and Hornwall [17]).

Freight wagons of the Austrian Railway Company are mainly equipped with cast iron brake shoes and do not include copper or zinc in significant concentrations. The chemical composition of brake linings of passenger wagons is similar to brake linings of motor vehicles. Therefore, copper and zinc concentrations of motor vehicle brakes as reported by Westerlund [15] were used. It was assumed that foreign trains that pass Villach are equipped with the same brakes as Austrian trains. The contact wire of railway tracks is exchanged approximately every 20 years after $15 \%$ of the wire is worn off. Based on these assumptions the emission of copper from contact wires in Villach is $8 \mathrm{~kg} / \mathrm{km}$ per year.

\subsection{Calculation of emissions}

Based on emission rates and data collection of kind and measures of copper and zinc surfaces total emissions are calculated. The most important surface emission 
sources of copper are brake linings of motor vehicles. The second largest emissions result from railway infrastructure, mainly by wear of the contact wire (figure 5).

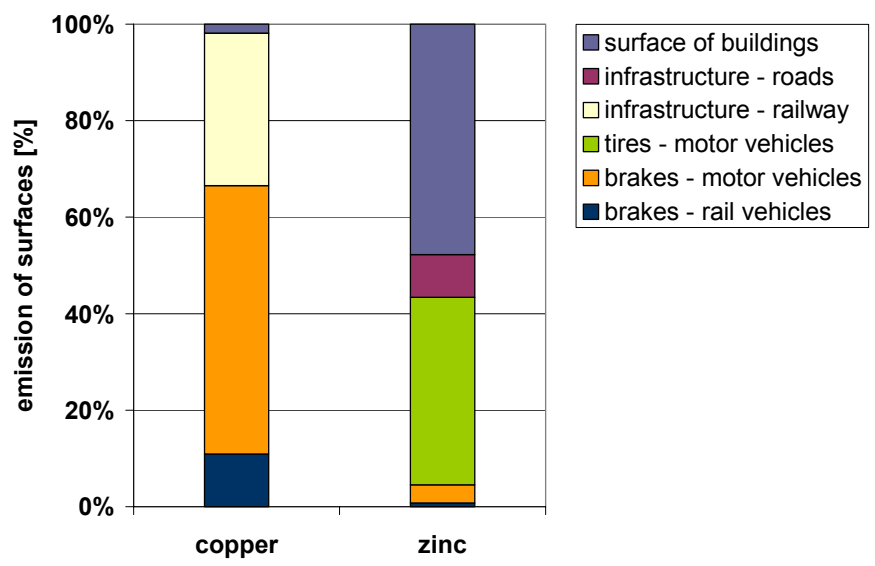

Figure 5: $\quad$ Surface emission sources of copper and zinc in Villach.

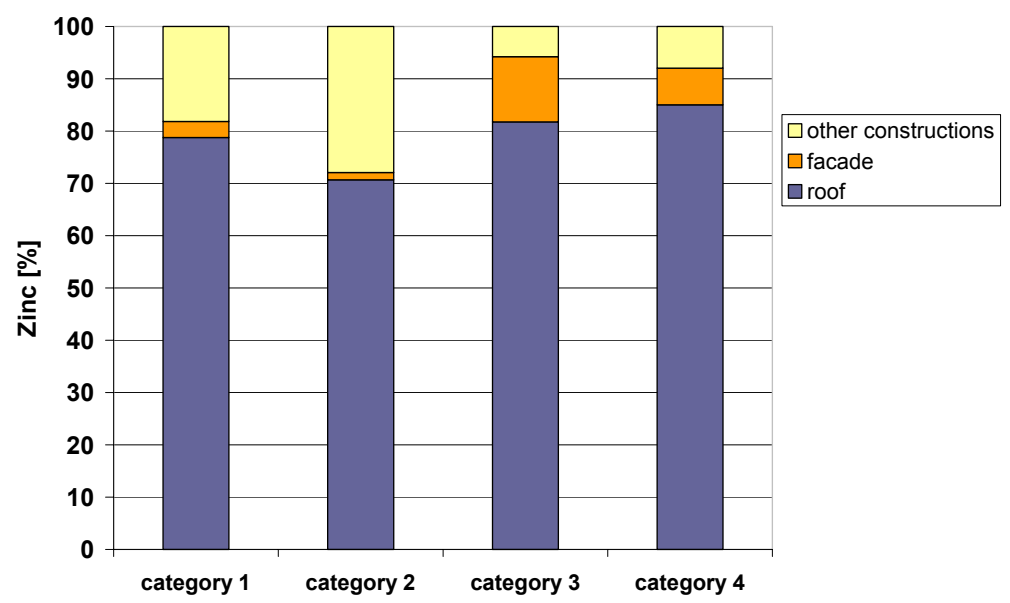

Figure 6: Zinc emission of building surfaces of different building categories.

Zinc is mainly emitted by surface materials of buildings and tires of motor vehicles. As copper is not a common roofing material in Villach hardly any copper is emitted by the surface of buildings. In figure 6 the percentage of zinc emissions of building surfaces of the different building categories is shown. In all categories roofs are the most important emission sources. Other sources include fences or banisters. 


\section{Conclusions}

So far there has been little attention on city surfaces as emission sources. This study has shown that surfaces release heavy metals. Copper is mainly emitted by traffic, which may cause heavy metal hot spots in soils next to streets and railway tracks. Zinc is largely emitted by roofing materials. However, it remains to be investigated which consequences the metal flows and possible accumulations in the environment have. In order to minimise emissions of surface materials the use of copper in brake linings should be prohibited. A substitution of copper in the railway contact wire is not probable in the coming years. However, it is necessary to respect the possibility of heavy metal hot spots next to railway lines in the management of these areas. As to zinc the focus should be on the management of surface water washed off by roofs. On-site infiltration could increase zinc amounts in soils. Therefore, sewer systems that enable treatment of surface waters should be prioritized towards other systems.

\section{References}

[1] United Nations. World Urbanization Prospects, The 1999 Revision. Online. http://www.un.org/esa/population/publications/wup1999/urbanization.pdf

[2] Bergbäck, B. Industrial Metabolism: The Emerging Landscape of Heavy Metal Immission in Sweden. Linköping University, Linköping, 1992.

[3] Landner, L. \& Lindeström, L., Zinc in society and in the environment. Swedish Environmental Research Group, Stockholm, Fryksta, 1998.

[4] Brunner, P.H. \& Rechberger, H., Practical Handbook of Material Flow Analysis. Lewis publishers, 2004

[5] Brunner, P.H. \& Rechberger, H., Anthropogenic metabolism and environmental legacies, in Encyclopedia of Global Environmental Change, Vol.3, Munn, T., Ed., John Wiley \& Sons, West Sussex, U.K., 2001. With permission.

[6] Lindström, M, Jonsson, A., Brolin, A.A. \& Håkanson, L., Heavy metal sediment load from the city of Stockholm. Water, Air and Soil Pollution: Focus 1: 103-118, 2001.

[7] Sörme, L., Goods in the anthroposphere as a metal emission source. Linköping University, Linköping, 2003.

[8] Bergbäck, B., Johansson, K. \& Mohlander U., Urban metal flows- a case study of Stockholm. Water, Air and Soil Pollution: Focus 1: 103-118, 2001.

[9] Naturvardsverket, Fordonstvätt: Allmänna Rad, 1996.

[10] Röschel, G. Personal communication, 2005, Municipality of Villach.

[11] Odnevall Wallinder, I., Verbiest, P., He, W. \& Leygraf, C., Effects of exposure direction and inclination on the runoff rates of zinc and copper roofs. Corrosion Science 42 (8): 1471-1487, 2000.

[12] Persson, D. \& Kucera, V., Metallutsläpp orsakade av korrosion och nedbrytning av olika materialytor. Korrosionsinstitutet. Stockholm, 1996.

[13] Lohm, U., Bergbäck, B., Hedbrant, J., Jonsson, A., Sviden, J., Sörme, L. \& Östlund, C., Databasen Stockhome: Flöden och ackumulation av metaller i 
Stockholms teknosfär. Tema Vatten i Natur och Samhälle. Linköping, 1997.

[14] Haider, R., Verunreinigungen von Straßenoberflächenwässern im Freilandgebiet: Übersicht mit detaillierter Analyse der Verschmutzungsquellen Fahr-bahnverschleiß, Reifenabrieb und Winterdienst. Institut für Verkehrswesen, Univ. of Natural Resources and Applied Life Sciences, Vienna, 1999.

[15] Westerlund, K.-G., Metalemissioner fran trafiken i Stockholm - slitage av bromsbelägg. Stockholms Luft- och Bulleranalys. Stockholm, 1998.

[16] Lindgren, A., Asphalt wear and pollution transport. The Science of the Total Environment 189/190: 281-286, 1996.

[17] Jacobson, T. \& Hornwall, F., Dubbslitage pa asfaltbeläggning: Sammanställning av resultat fran provvägar och kontrollsträckor 1990 1998. Statens Väg- och Transportforskning-sinstitut. Linköping, 1999. 